\title{
ESTRATÉGIAS DE OPERAÇÕES E TECNOLÓGICAS DE EMPRESAS DO SETOR DE LINHA BRANCA
}

\section{OPERATIONS AND TECHNOLOGY STRATEGIES OF COMPANIES BELONGING TO THE HOME-APPLIANCE INDUSTRY SEGMENT}

\author{
Aline Lamon Cerra ${ }^{1}$; Naiara Calife ${ }^{2}$; Edemilson Nogueira ${ }^{3}$ Jonas Lucio Maia ${ }^{4}$; Alceu Gomes Alves \\ Filho $^{5}$ \\ ${ }^{1}$ Universidade Federal de São Carlos - UFSCar - São Carlos/SP - Brasil \\ alinelc@terra.com.br \\ ${ }^{2}$ Universidade Federal de São Carlos - UFSCar - São Carlos/SP - Brasil \\ naiaracalife@,hotmail.com \\ ${ }^{3}$ Universidade Federal de São Carlos - UFSCar - São Carlos/SP - Brasil \\ edn@power.ufscar.br \\ ${ }^{4}$ Universidade Federal de São Carlos - UFSCar - São Carlos/SP - Brasil \\ jonasmaia@dep.ufscar.br \\ ${ }^{5}$ Universidade Federal de São Carlos - UFSCar - São Carlos/SP - Brasil \\ alceu@power.ufcar.br
}

\begin{abstract}
Resumo
O objetivo do trabalho é estudar as Estratégias de Operações (EOs) e Estratégias Tecnológicas (ETs) de duas montadoras do setor de linha branca, comparando-as, para em um segundo momento discutir a conexão entre ambas as estratégias no setor mencionado. Para atingir os objetivos do trabalho, são realizados estudos nas duas montadoras, fundamentados em entrevistas semi-estruturadas. Os resultados mostram que, para alcançar prioridades competitivas semelhantes, essas montadoras implementam mudanças semelhantes nas áreas de decisão, apesar de algumas diferenças também terem sido identificadas. Além disso, adotam ETs semelhantes, no que se refere às Capacidades Tecnológicas por elas priorizadas. No entanto, apesar de despenderem esforços para as mesmas capacidades (Inovação, Investimento (Aquisição) $e$ Produção e Adaptação), os esforços que cada uma delas direciona a cada uma delas são distintos.
\end{abstract}

Palavras-Chave: Estratégia de Operações. Estratégia Tecnológica. Setor de Linha Branca.

\section{Introdução}

Os temas relacionados à Estratégia de Operações (EO) e Estratégia Tecnológica (ET) foram (e vêm sendo) desenvolvidos de maneira independente teoricamente, em duas linhas bem estabelecidas de pensamento, tendo havido até o momento raras tentativas de conexão. 
$\mathrm{Na}$ literatura sobre EO, a tecnologia aparece como uma das áreas de decisão estruturais, subordinada portanto à EO. Na literatura sobre ET, a produção (ou o conjunto de operações) aparece ou como uma das áreas onde são implementados programas de capacitação, ou como objeto de esforços de melhorias e de mudanças técnicas. Os autores de artigos em um campo raramente são autores no outro, e não há tentativas (ensaios) de tratamento desses dois tipos de estratégias como igualmente importantes (para a estratégia competitiva da empresa) (ALVES FILHO et al, 2005).

Neste artigo pretendemos abordar as possibilidades de integração da EP com a ET no setor de linha branca.

Produtos da linha branca referem-se a uma denominação dada aos eletrodomésticos nãoportáteis que, devido às suas características peculiares, são considerados um segmento específico de eletrodomésticos. Segundo Matusita (1997), o que os diferencia dos demais produtos da indústria de eletrodomésticos é a maturidade tecnológica, já que não apresentam inovações fundamentais mesmo quando novos produtos são lançados.

Os produtos considerados como linha branca são: refrigeradores, lavadoras automáticas, freezers verticais e horizontais, lava-louças, secadoras de roupas automáticas, fogões, condicionadores de ar e fornos microondas (ROTTA, 2004).

Neste contexto, a questão desta pesquisa é "Como pode ser entendida a conexão da EO e ET de empresas do setor de linha branca?" Assim, o objetivo do trabalho é estudar as EOs e ETs de duas montadoras, comparando-as, para em um segundo momento discutir a conexão entre ambas as estratégias no setor mencionado.

Para atingir os objetivos do trabalho, são realizados estudos nas duas montadoras, fundamentados em entrevistas semi-estruturadas. Nas empresas, as pessoas entrevistadas são aquelas ligadas à tecnologia de produtos e processos, ou seja, diretores ligados à área tecnológica, diretores industriais, além de gerentes de produção.

$\mathrm{O}$ artigo se encontra estruturado da seguinte forma: inicialmente é apresentada a síntese da literatura sobre EO e ET, respectivamente. A seguir são apresentados os estudos de caso. Concluindo, têm-se as considerações finais do trabalho.

\section{Estratégia de Operações}

$\mathrm{Na}$ literatura sobre Estratégia de Operações (EO), denominações distintas têm sido utilizadas. O termo inicialmente cunhado foi "estratégia de manufatura", evoluindo para "estratégia de produção", e atualmente para "estratégia de operações". Contudo, faz-se necessário ressaltar que estas expressões diferentes não decorrem de mudanças nos conceitos e fundamentos teóricos, tendo 
as duas últimas sido propostas de modo a contemplar as aplicações também na gestão de serviços, além de na gestão da manufatura.

É atribuída a William Skinner a elaboração do conceito inicial sobre este assunto, através de seu artigo "Manufacturing - Missing Link in Corporate Strategy" (SKINNER, 1969). Para o autor, a relação entre a estratégia da empresa e a manufatura não era facilmente compreendida, embora a política de produção necessitasse ser especificamente projetada para atender as necessidades definidas no nível estratégico.

Diversas definições para o conceito de Estratégia de Operações podem ser encontradas na literatura, cada uma enfocando um aspecto particular da gestão de operações, ou uma escola de pensamento a respeito de estratégia. Será aqui adotada a definição de Hayes et al (2004), para os quais “a estratégia de operações é um conjunto de objetivos, políticas e restrições auto-impostas que conjuntamente descrevem como a organização se propõe a dirigir e desenvolver todos os recursos investidos nas operações, de forma a melhor executar (e possivelmente redefinir) sua missão".

$\mathrm{Na}$ definição acima apresentada, podem-se identificar duas orientações estratégicas distintas, porém complementares. Quando os autores comentam sobre objetivos e políticas, direcionamento de investimentos e execução da missão, estes se pautam na escola de planejamento estratégico - um processo formal e top-down que abrange o plano estratégico, tático e operacional (OLIVEIRA, 2001). No entanto, quando tratam de restrições auto-impostas e redefinição de missão, estes se referem às competências estudadas pela visão baseada em recursos (RBV - Resource Based View). A RBV advoga que as competências e recursos intangíveis das empresas são as origens da vantagem competitiva, sendo que tais recursos e competências desenvolvidos no presente e no passado condicionarão o direcionamento estratégico do futuro. (COLLIS e MONTGOMERY, 1995).

Sob a ótica do planejamento estratégico, a Estratégia de Operações é uma estratégia funcional e, portanto, deve promover sustentação à estratégia competitiva. Dado o fato dos elementos que compõem o sistema produtivo terem de ser concebidos para atingir determinados fins e realizar determinadas tarefas, estratégias competitivas diferentes poderão exigir configurações distintas do sistema de produção. Neste sentido, cada tipo de estratégia demanda certas tarefas da produção e especifica determinados objetivos, os quais são conhecidos por "prioridades competitivas" e foram inicialmente identificados por Skinner (1969) como sendo produtividade, serviço, qualidade e retorno sobre investimento.

Em trabalhos subseqüentes, outros autores apresentaram diferentes combinações de prioridades como, por exemplo, custo, qualidade, confiabilidade e flexibilidade (HAYES e WHEELWRIGHT, 1984; WARD e DURAY, 2000; KATHURIA, 2000; e DEMETER, 2003). A este conjunto, Hill (2000) e Slack, Chambers e Johnston (2002) adicionaram uma dimensão relativa 
à velocidade, e Dangayach e Deshmukh (2003) contemplaram ainda o aspecto inovação. Embora o aspecto velocidade seja aqui considerado, a inovação será aqui tratada como agente facilitador das outras prioridades competitivas, possibilitando, por exemplo, ampliar a flexibilidade de introdução de novos produtos, reduzir de custos através do reprojeto de processos, etc.

Frente a estas considerações, o modelo de prioridades que será aqui adotado é o de Garvin (1993), que apresenta as prioridades como sendo custo, qualidade, entrega, flexibilidade e serviço. Este modelo, com ampla aceitação na literatura, ainda desdobra as prioridades competitivas em várias sub-prioridades, conforme mostra a Tabela 1.

Tabela 1 - Subprioridades competitivas da produção

\begin{tabular}{|c|c|c|c|c|c|}
\hline & Custo & Qualidade & Entrega & Flexibilidade & Serviço \\
\hline 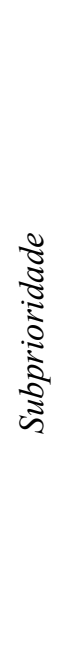 & $\begin{array}{l}\text { - Custo inicial } \\
- \text { Custo } \\
\text { operacional } \\
\text { - Custo de } \\
\text { manutenção }\end{array}$ & $\begin{array}{l}\text { - Desempenho } \\
\text { - Características } \\
\text { - Confiabilidade } \\
\text { - Conformidade } \\
\text { - Durabilidade } \\
\text { - Nível de serviço } \\
\text { - Estética } \\
\text { - Qualidade } \\
\text { percebida }\end{array}$ & $\begin{array}{l}\text { - Precisão } \\
\text { - Completude } \\
\text { - Confiabilidade } \\
\text { - Disponibilidade } \\
\text { - Velocidade } \\
\text { - Disponibilidade de } \\
\text { informação } \\
\text { - Facilidade de } \\
\text { emissão de pedidos } \\
\text { - Qualidade } \\
\text { - Flexibilidade de } \\
\text { emissão de pedidos } \\
\text { - Flexibilidade de } \\
\text { transporte } \\
\text { - Facilidade de } \\
\text { retorno }\end{array}$ & $\begin{array}{l}- \text { Flexibilidade de } \\
\text { produto } \\
-\quad \text { Flexibilidade de } \\
\text { Volume } \\
-\quad \text { Flexibilidade de } \\
\text { Processo }\end{array}$ & $\begin{array}{l}\text { - Apoio ao } \\
\text { cliente } \\
\text { - Apoio às } \\
\text { vendas } \\
\text { - Resolução de } \\
\text { problemas } \\
\text { - Informação }\end{array}$ \\
\hline
\end{tabular}

Fonte: Adaptado de Garvin (1993)

As prioridades competitivas variam conforme as diferentes circunstâncias competitivas e a estratégia da empresa. Além disso, não há um consenso sobre quais devam ser os conjuntos delas que orientam a implementação da estratégia de operações.

Segundo Nogueira (2002), um aspecto importante a ser considerado quando se projeta ou opera um sistema de produção é a necessidade da realização de trade-offs. Ao menos na visão tradicional, variáveis como custo, qualidade, flexibilidade, entrega e serviço ao cliente colocam a administração constantemente diante de situações de decisão em que escolhas são inevitáveis.

A proposição da necessidade de realização de trade-offs tem sido responsável por umas das principais controvérsias existentes na literatura relativa ao conceito de estratégia de operações. Como exemplo desta discordância, diversos autores desenvolvem e advogam suas idéias em pelo menos três diferentes correntes de pensamento: a visão tradicional, a cumulativa e a integrativa (BOYER e LEWIS, 2002).

Através da visão tradicional de trade-offs, segue-se a linha de pensamento de Skinner (1969), para quem as escolhas entre enfatizar uma ou outra prioridade competitiva serão inevitáveis, 
nas mais diversas circunstâncias.

Na visão cumulativa, Ferdows e De Meyer (1990) criticam a visão tradicional a respeito de incompatibilidades entre as prioridades competitivas. Esses autores, a partir de uma pesquisa que desenvolveram na década de oitenta em empresas européias, japonesas e norte-americanas, verificaram que várias empresas estavam obtendo bons desempenhos em algumas das prioridades competitivas ao mesmo tempo. Baseados nesta pesquisa, eles puderam propor o "modelo do cone de areia", em que as capacidades poderiam ser acumuladas e "construídas" umas sobre as outras.

Buscando uma combinação das duas visões anteriores, a visão integrativa prega que os elementos de ambos os pontos de vista são aplicáveis. Como exemplos desta visão, tem-se: (1) o "modelo pivô" de Da Silveira e Slack (2001), para os quais existem certas escolhas a serem realizadas entre as prioridades (como os dois extremos de uma gangorra), mas o acumulo de competências faz com que todas as prioridades competitivas tenham seus níveis absolutos aumentados (elevando a altura do pivô da gangorra) e (2) a compatibilidade das prioridades dentro de determinadas faixas de desempenho, proposta por Alves Filho, Pires e Vanalle (1995).

Também adotando a visão integrativa, Hayes et al (2004) comentam a existência de tradeoffs de primeiro (impacto no presente) e segundo (impacto no futuro) graus. Desta forma, as escolhas estratégicas realizadas no presente não somente direcionarão as operações hoje, mas condicionarão as possibilidades estratégias no futuro, em um fenômeno conhecido como “dependência de trajetória" (do inglês, path dependence).

Assim, pode-se considerar que os trade-offs continuam sendo um elemento importante na teoria a respeito da estratégia de operações, embora tenham ocorrido nos últimos trinta anos significativas mudanças tecnológicas, surgido novas demandas da sociedade, mudado os perfis dos consumidores e ocorrido ainda outras mudanças no ambiente que afetaram o projeto e a operação dos sistemas produtivos e, assim, a natureza e os tipos de objetivos da produção.

As prioridades competitivas refletem necessidades da estratégia competitiva e apontam para determinados objetivos a serem atingidos pelo sistema produtivo. Para se alcançar esses objetivos, é necessário o desenvolvimento de um padrão de ações relacionadas a um conjunto de áreas de decisões. Em seu trabalho inicial, Skinner (1969), sugere cinco áreas de decisão: planta e equipamento, planejamento e controle da produção, mão-de-obra e estrutura administrativa, projeto do produto / engenharia, e organização e administração.

A partir da proposição de Skinner, Hayes et al (1988) propuseram uma nova classificação, com dez áreas de decisão, agrupadas sob duas categorias: estruturais e infra-estruturais. 
Tabela 2 - Áreas de decisão em estratégia de produção

\begin{tabular}{|c|c|c|}
\hline & Decisões Estruturais & Decisões Infra-Estruturais \\
\hline 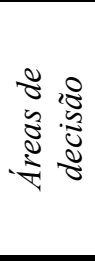 & $\begin{array}{ll}\text { - } & \text { Capacidade } \\
\text { - } & \text { Instalações } \\
\text { - } & \text { Tecnologia } \\
\text { - } & \text { Integração Vertical }\end{array}$ & $\begin{array}{l}\text { - Recursos Humanos } \\
\text { - Qualidade } \\
\text { - Planejamento e controle da produção / materiais } \\
\text { - Novos produtos } \\
\text { - Medidas de desempenho } \\
\text { - Organização }\end{array}$ \\
\hline
\end{tabular}

Fonte: Adaptado de HAYES et al (1988) apud NOGUEIRA (2002)

As decisões estruturais de uma operação produtiva são as que influenciam principalmente as atividades de projeto, enquanto as decisões de infra-estrutura são as que influenciam a força de trabalho e as atividades de planejamento, controle e melhoria (SLACK, CHAMBERS \& JOHNSTON, 2002). As decisões estruturais possuem impactos no longo prazo, sendo difíceis de serem revertidas ou modificadas e exigem vultosos investimentos de capital. As decisões de natureza infra-estruturais estão relacionadas a aspectos mais operacionais do negócio, possuindo resultados tanto no curto, no médio e no longo prazo.

Esta seção buscou realizar uma síntese teórica a respeito da Estratégia de Operações e de seus principais elementos, síntese esta que fornecerá os subsídios para a realização e análise dos casos a seguir descritos.

\section{Estratégia Tecnológica}

A variedade de conceitos sobre tecnologia encontrada na literatura é, de acordo com Alves Filho (1991), conseqüência de diferentes visões e objetivos dos pesquisadores. Iglecias (2001) aponta algumas características comuns à maioria das definições apresentadas: a tecnologia é oriunda das ciências; deve ser orientada para um fim prático; deve ser reproduzida em escala industrial; e pode ser aplicada não apenas a bens e serviços, mas também ao processo produtivo e à sua gestão.

O fator chave da ET é o entendimento por parte da firma da importância de uma variedade de tecnologias, interna e externamente (Ford e Thomas, 1997; Zahra, 1996). Assim, aquisição externa versus desenvolvimento interno de tecnologias, e o conhecimento do momento exato em que a firma deve alternar cada um deles tem sido a decisão crucial para gerentes de firmas baseadas em tecnologia (JONES et al, 2001 apud HARO-DOMINGUES et al, 2007).

Neste contexto, deve-se levar em conta a capacidade de absorção (absorptive capability) (COHEN e LEVINTHAL, 1990). Unidades com alto nível de capacidade de absorção provavelmente exploram melhor novos conhecimentos provenientes de outras unidades para dar 
suporte às suas aquisições de tecnologias.

Para Davenport, Campbell-Hunt e Solomon (2003), o desenvolvimento tecnológico da firma deve ser visto como um processo de co-evolução, envolvendo outras entidades (clientes, parceiros de negócios, fornecedores e os demais agentes externos à empresa). Estes autores indicam que este é um entendimento dinâmico da ET que envolve um processo não-linear de realimentação (feedback); desse modo, uma mudança inicial é reforçada (ou não) por ciclos recorrentes de experiências. Com base nas experiências, a firma vai traçando sua trajetória, que é única para cada sistema ou sub-sistema.

Há ainda muito debate de como definir o conceito de Estratégia Tecnológica (CLARKE et al, 1995), não havendo portanto um conceito consagrado de ET.

Gibbons e O`Conner (2003) definem Estratégia Tecnológica como um conjunto de escolhas que a firma faz sobre o estado e qualidade do know-how incorporado a projeto, desenvolvimento e produção de seus produtos e/ou serviços.

Para Solomon (2001) apud Davenport, Campbell-Hunt e Solomon (2003), a Estratégia Tecnológica abrange a aquisição, gestão e exploração de conhecimentos e recursos tecnológicos da organização para alcançar suas metas de negócios.

Neste trabalho, entendemos a Estratégia Tecnológica como um conjunto de esforços da empresa que visa aumentar suas capacidades tecnológicas e implementar mudanças, seja nos sistemas produtivos, seja em produtos e processos:

A Estratégia Tecnológica diz respeito a um conjunto de esforços e ações da empresa no sentido de ampliar sua capacidade tecnológica, tanto no âmbito das atividades de P\&D como nas demais áreas da empresa, para a implementação da mudança técnica. Engloba esta última a criação de novas técnicas e mudanças não necessariamente novas nos elementos que compõem e caracterizam um sistema de produção, seja do ponto de vista da empresa, seja em relação às fronteiras internacionais (ALVES FILHO, 1991:27).

Adotamos o conceito de Alves Filho (1991) que utiliza o termo mudança técnica para se referir às mudanças nos elementos que compõem e caracterizam um sistema de produção. Pavitt e Bell (1993) definem a mudança técnica como sendo a introdução de tecnologias em novos produtos ou processos através de investimentos, ou ainda, adaptação incremental e melhoria da capacidade de produção existente.

Quanto à capacidade tecnológica, Bell e Pavitt (1993) a definem como os "recursos necessários para gerar e administrar mudanças técnicas, incluindo habilidades, conhecimentos e experiências e estruturas e links institucionais". A mudança técnica, segundo estes mesmos autores trata-se de qualquer maneira na qual uma nova tecnologia é incorporada dentro da capacidade de produção de firmas e economias. 
Dahlman, Ross-Larson e Westphal (1987), Westphal, Kim e Dahlman (1985) apud Alves Filho (1991) sugerem três tipos de capacidades abarcadas pela ET:

- Capacidade de Inovação: para criar novas tecnologias, desenvolver novos produtos ou serviços. Trata-se da capacidade para introduzir mudanças técnicas (radicais ou incrementais).

- Capacidade de Investimento: para adquirir tecnologia, para substituir, expandir e implantar instalações, adaptadas às condições de investimento;

- Capacidade de Produção e adaptação: para operar as instalações produtivas, tendo em vista a obtenção de eficiência produtiva; abrange, além da produção, as possíveis adaptações da tecnologia.

Ford (1989) sugere uma quarta capacidade, a Capacidade de Exploração e Proteção de Tecnologias, para vender ou prestar serviços no mercado a partir de tecnologias dominadas e também para implementar medidas que impeçam que conhecimentos adquiridos sejam copiados por concorrentes.

As fronteiras entre esses quatro tipos de capacidade tecnológica não são claras, mas é certo que investimentos e esforços específicos são requeridos para cada tipo de capacidade (WESTPHAL, KIM e DAHLMAN (1985) apud ALVES FILHO (1991)).

Com base neste conceito, estabelecemos os elementos de uma ET que são analisados na prática das empresas estudadas: as Capacidades Tecnológicas.

Para isso, nas empresas foram levantadas as informações conforme demonstra o Quadro a seguir:

Quadro 1- Indicadores para a avaliação das Capacidades Tecnológicas.

\begin{tabular}{|l|l|l|}
\hline $\begin{array}{l}\text { Capacidade de } \\
\text { Inovação }\end{array}$ & $\begin{array}{l}\text { A existência de P\&D estruturado ou não empresa; a autonomia tecnológica da subsidiária em } \\
\text { relação à matriz estrangeira; o número de engenheiros/cientistas que trabalham em DP; as } \\
\text { fases do DP, o lançamento de novos produtos, os projetos recentes e a introdução de } \\
\text { mudanças significativas em processos de produção; e o envolvimento dos fornecedores nas } \\
\text { atividades de DP local. }\end{array}$ \\
\hline $\begin{array}{l}\text { Capacidade de } \\
\text { Investimento } \\
\text { (Aquisição) }\end{array}$ & $\begin{array}{l}\text { Os projetos de aquisição de nova tecnologia para a empresa; a relação com centros de } \\
\text { pesquisa e universidades para o desenvolvimento de projetos e/ou aquisição de tecnologia; e a } \\
\text { participação em redes de cooperação para desenvolvimento de novas tecnologias. }\end{array}$ \\
\hline $\begin{array}{l}\text { Capacidade de } \\
\text { Produção } \\
\text { Adaptação }\end{array}$ & e & $\begin{array}{l}\text { As mudanças incrementais (e as fontes dessas mudanças) em produtos e processos de } \\
\text { produção; e a estrutura organizacional que viabiliza os contatos entre a Engenharia e a fábrica. }\end{array}$ \\
\hline $\begin{array}{l}\text { Capacidade de } \\
\text { Exploração } \\
\text { de Proteção }\end{array}$ & e & $\begin{array}{l}\text { A existência de projetos nas empresas de exploração comercial de tecnologias dominadas (se a } \\
\text { empresa compra ou licencia tecnologias de produto e processo desenvolvidas por outras } \\
\text { empresas para incorporar em seus próprios produtos e processos e se explora (vende) } \\
\text { tecnologias por ela desenvolvidas). } \\
\text { As medidas implementadas para que o conhecimento adquirido não seja passado para a } \\
\text { concorrência. }\end{array}$ \\
\hline
\end{tabular}

Fonte: elaborado pelos autores 


\section{Estudos de caso}

Neste tópico apresentamos alguns dos resultados obtidos com as entrevistas e visitas realizadas em duas fabricantes de produtos da linha branca instaladas no Brasil, adquiridas por grupos multinacionais em períodos diferentes.

A primeira delas, aqui denominada "Montadora A", apresenta cinco plantas no Brasil; já o grupo ao qual a "Montadora B" pertence, possui duas. Cabe mencionar que as características tratadas neste trabalho referem-se apenas às plantas estudadas.

As atividades tecnológicas (tanto pesquisa básica e aplicada quanto desenvolvimento de produtos/processos) são mais descentralizadas na Montadora $\mathrm{A}$, quando comparada à Montadora $\mathrm{B}$. Nesta última, há grande centralização de atividades de engenharia na matriz estrangeira, onde os projetos dos produtos são desenvolvidos.

Neste contexto, no caso da Montadora A há um setor de Engenharia (P\&D) no Brasil, porém não está situado na planta estudada; nesta última, há dez pessoas que interagem com os engenheiros do mencionado setor e com a matriz estrangeira. No caso da Montadora B, o setor de P\&D está situado na matriz estrangeira; na planta estudada há um gerente de Engenharia, que conta com o apoio de dez engenheiros, e que faz a integração com o setor estrangeiro onde os produtos são desenvolvidos.

\subsection{Estratégia de Operações}

Nesta seção, discorre-se a respeito da Estratégia de Operações das duas empresas estudadas. Para isso, serão abordadas, de modo comparativo, as prioridades competitivas e as principais características das áreas de decisão de cada uma delas.

- Prioridades competitivas: ambas priorizam a redução de custos, embora este aspecto seja a segunda prioridade da empresa "A" e a primeira prioridade da empresa "B". Complementando, a empresa "A", por sua vez, tem como primeira prioridade a flexibilidade de produtos, enquanto a flexibilidade de volume é a segunda prioridade de "B".

Dessa forma, uma diferença que pôde ser verificada se refere ao aspecto da flexibilidade de introdução de novos produtos, fato que parece ser corroborado pelos esforços da empresa A no sentido de dar corpo a seu departamento interno de desenvolvimento de produtos.

Neste contexto, a empresa "A" realiza desenvolvimento de produtos localmente no Brasil, ao passo que a empresa "B" adota a abordagem de plataformas continentais, e tem seu DP eminentemente centralizado no exterior. 
- Instalações e Capacidade: Desse modo, a Montadora A, com cerca de 1300 funcionários, produz lavadoras de roupas, refrigeradores e fogões, totalizando 110.000 produtos/mês. Já a Montadora B, que possui 800 funcionários, produz aproximadamente 51.000 fogões/mês. Considerando a média anual, ambas operam com capacidade ociosa ( $75 \%$ no caso de "A" e $70 \%$ no caso de "B").

Cabe mencionar que a demanda no setor é sazonal - a partir de meados do segundo semestre há grande pico da demanda.

- Tecnologias de Processo: ambas têm buscando aumentar o nível de automatização das linhas. Na Montadora B, o processo ainda é predominantemente manual.

- Gestão de Suprimentos: a tendência da redução do número de fornecedores foi verificada em ambas as montadoras estudadas. No setor de linha branca os fornecedores são, em sua maioria, comuns às diversas montadoras e localizados nas regiões Sul e Sudeste do país.

As empresas estudadas, no entanto, se diferem quanto à política de suprimentos adotada: a Montadora A possui dois fornecedores por item no caso dos componentes terceirizados que são considerados mais importantes em termos de conteúdo tecnológico e, um fornecedor, no caso de itens mais simples - os quais procuram adquirir de fornecedores de menor porte que a atendem quase que exclusivamente. Já a Montadora B possui dois fornecedores por item e seus fornecedores são, em geral, empresas de médio e grande porte. Isso implica dizer que o desenvolvimento de fornecedores deve ser mais comum no caso de A.

- Terceirização de componentes: a Montadora A faz internamente as peças - metálicas e poliméricas - de maior porte, adquirindo as demais de fornecedores. A Montadora B é considerada verticalizada na produção de fogões.

- Organização do Trabalho: a Montadora A pode ser considerada uma planta operativa, pois as áreas administrativas (Engenharia, Compras, etc) estão centralizadas na matriz brasileira. Já a Montadora B possui essas áreas em sua planta. Ambas implementaram um sistema de produção baseado no modelo de Produção Enxuta - no caso de B, ainda está sendo consolidado.

No chão de fábrica, a força de trabalho é dividida em times, no caso de A, e em células, no caso da Montadora B.

- Recursos Humanos: a escolaridade mínima exigida na produção é segundo grau completo, na Montadora A. Na Montadora B exige-se o primeiro grau completo. A Montadora A opera em 2 turnos, mas nas linhas de metalurgia e de manutenção são três turnos de trabalho. A Montadora B utiliza três turnos, mas nos períodos de pico da demanda pode haver quatro.

- PCP: Ambas as empresas trabalham em misto de produção contra estoque e contra carteira,

- Logística: a empresa "A" realiza milk run terceirizado com seus fornecedores, dado que a maioria dos mesmos se situam a aproximadamente 100 a $150 \mathrm{~km}$ da fábrica. 
Gestão da Qualidade: as empresas parecem estar em patamares bastante distintos: enquanto "A" já é certificada pelas principais normas, e apresenta o uso de ferramentas clássicas da qualidade, a empresa "B" ainda busca suas certificações e o estabelecimento de um programa de qualidade total.

Contudo, como o aspecto qualidade não figura entre as prioridades competitivas de "B", podese conjeturar que as ferramentas de qualidade que "B" utiliza já permitem um nível de qualidade de produto aceitável por seus clientes, sendo a exigência de normas de certificação ou de programas mais amplos de qualidade relegados a segundo plano.

Gestão da Tecnologia e Desenvolvimento de Produtos: as principais características podem ser observadas na seção a seguir, que trata das Estratégias Tecnológicas (ETs) das empresas.

\subsection{Estratégia Tecnológica}

Nesta seção, discorre-se a respeito da Estratégia Tecnológica das duas empresas estudadas. Para isso, serão abordadas, de modo comparativo, as Capacidades Tecnológicas de cada uma delas.

Em linhas gerais, tem-se que: buscando obter mais flexibilidade e reduzir custos, a Montadora A despendendo esforços para desenvolver as Capacidades de Inovação, Investimento e de Produção e Adaptação. A Montadora B, buscando reduzir custos e em períodos de pico da demanda ampliar a flexibilidade, vem ampliando as capacidades de Inovação, Investimento e de Produção e Adaptação.

Embora as Capacidades Tecnológicas priorizadas sejam as mesmas para as duas montadoras, poderá ser visto a seguir que os esforços que cada uma delas despende à elas são diferentes. As semelhanças quanto às capacidades priorizadas devem, em grande parte, estar relacionadas às demandas do próprio setor ao qual estão inseridas.

- Capacidade de Inovação: O setor voltado às atividades tecnológicas (desenvolvimento de processos) situado na Montadora A ampliou suas atividades de apoio ao setor de Desenvolvimento de Produtos (que é situado em outra planta do grupo instalada no Brasil, onde produtos são desenvolvidos localmente com grande autonomia tecnológica em relação à matriz estrangeira). Assim, passou a ter maior autonomia para alterar processos de produção.

No caso da Montadora B, a estratégia adotada (a nível corporativo) foi a de implementar produtos com plataformas continentais. Desse modo, os produtos são desenvolvidos na matriz estrangeira. Engenheiros da Montadora B (que realizam atividades de desenvolvimento de processos) aumentaram a autonomia mediante a matriz para introduzir (pequenas) adaptações em produtos desenvolvidos no exterior e alterar processos.

Assim, ao comparar a autonomia concedida à estrutura de Desenvolvimento de Produtos das montadoras estudadas, constamos que uma delas (Montadora A) desenvolve produtos localmente, 
voltados principalmente ao mercado nacional, enquanto a outra (Montadora B), desenvolve os produtos na matriz estrangeira e seus produtos são vendidos para vários países da América Latina, Ásia e Leste Europeu.

Deve-se considerar ainda que a Montadora A foi adquirida por grupo multinacional cerca de dez anos antes que $\mathrm{B}$, de modo que a influência da matriz estrangeira deva ser maior, pelo menos no que diz respeito à implementação de técnicas, ferramentas e práticas de gestão, melhorias nas instalações, etc. Além disso, a diversidade de produtos é maior na Montadora A, embora sua capacidade instalada de produção seja inferior à de B.

Capacidade de Investimento (Aquisição): A Montadora A busca por conhecimentos tecnológicos junto à matriz estrangeira, mas, para $\mathrm{B}$, a matriz estrangeira é a principal fonte de conhecimentos tecnológicos - onde os produtos são desenvolvidos. Para ambas, fornecedores especializados no desenvolvimento de produção de componentes importantes também são considerados fontes de conhecimento. Com universidades os contatos dessas empresas são frequentes, para realizar testes e receber serviços de consultorias.

Capacidade de Produção e Adaptação: Na Montadora A há um programa (corporativo) que visa maior integração entre o desenvolvimento de produtos e o de processos. Atualmente a planta apresenta maior autonomia para alterar processos e faz a ponte entre o setor de DP e a fábrica. $\mathrm{Na}$ Produção foram implantados programas e técnicas visando reduzir custos.

A Montadora B também vem apresentando maior autonomia para alterar processos e os engenheiros responsáveis fazem a ponte entre o setor de DP e a fábrica.

No que se refere às demais capacidades (Capacidade de Exploração e Proteção), vale ressaltar que as montadoras não têm demonstrado esforços no sentido de ampliá-las.

\section{Considerações Finais}

A indústria de linha branca chegou ao Brasil no final dos anos 40, na fase inicial da política de substituição de importações. O setor ficou caracterizado por um número reduzido de grandes empresas familiares de capital nacional e dois grandes grupos transnacionais, que dominavam, direta ou indiretamente, as demais companhias, formando um oligopólio (MARTINEZ, 2004).

O crescimento da demanda por estes produtos nos países desenvolvidos e o aumento de sua difusão ocorreu na década de 70. No entanto, verificou-se na década seguinte um processo de desaceleração da demanda nesses países, chegando a um período de estagnação nos anos 90 . Segundo Rotta (2004), nos Estados Unidos e Europa presenciava-se a saturação dos mercados.

Com isso, os grandes grupos internacionais procuraram novos mercados, voltando-se para os mercados emergentes como a América Latina, o Leste Europeu e o Sudeste Asiático. As empresas 
brasileiras foram gradualmente sendo incorporadas por poucos e grandes grupos estrangeiros, ganhando acesso a inovações e iniciando um processo de rearranjo patrimonial que acompanhava a tendência mundial (GITAHY e CUNHA, 1998 apud MARTINEZ, 2004). Uma das principais conseqüências foi a desnacionalização do capital produtivo que, até então, tinha forte participação de empresas familiares nacionais.

Mais especificamente, foi a partir da metade da década de noventa que se intensificou o processo de reestruturação produtiva e organizacional nas indústrias nacionais, que diferenciaram e sofisticaram os produtos, ampliaram a capacidade produtiva, modernizando ou abrindo novas plantas (ROTTA, 2004).

Neste setor, os investimentos externos possibilitaram a difusão de tecnologias no Brasil permitindo a paridade de desempenho internacional tanto em processos, quanto no lançamento de novos produtos. Este último foi um grande avanço para o mercado brasileiro, que ofertava produtos obsoletos frente aos mercados de suas matrizes.

Assim, as empresas do setor de linha branca foram sendo adquiridas por grandes grupos multinacionais e os conhecimentos tecnológicos locais acumulados (assim como as instalações) foram de certa forma aproveitados, ao mesmo tempo em que as empresas foram se modernizando e tendo acesso a inovações provenientes das matrizes estrangeiras.

O planejamento estratégico propicia que a empresa identifique em que direção predominante pretende mover-se, orientando as competências (que vai acumulando e adquirindo) para as oportunidades que surgem no mercado de criar valor para seus clientes atuais e potenciais.

As Montadoras A e B apresentam as mesmas prioridades competitivas, porém com pequena diferença em relação à ordem de importância dada. Isso explica o fato de implementarem algumas mudanças nas áreas de decisão também semelhantes.

Considerando primeiramente as semelhanças, a título de ilustração pode-se citar o fato de ambas operarem com capacidade ociosa, estarem buscando aumentar o nivel de automação, apresentarem a tendencia à redução da base de fornecedores, implementarem sistemas de produção baseados na Produção Enxuta, etc.

Apesar das semelhanças, diferenças importantes são observadas - as diferentes políticas de suprimentos adotadas, os diferentes níveis de terceirização, a Gestão da Qualidade, dentre outras. Pode-se dizer que parte dessas diferenças dizem respeito às características estruturais e relacionais das cadeias de suprimentos aos quais estão inseridas - a Montadora A optou por manter um conjunto de fornecedores de menor porte, que a atendem esclusivamente (ou quase exclusivamente) e que necessitam de seu auxílio para desempenhar as atividades. 
Para prioridades competitivas semelhantes, essas montadoras adotam ETs semelhantes, no que se refere às Capacidades Tecnológicas por elas priorizadas. No entanto, apesar de despenderem esforços para as mesmas capacidades (Inovação, Investimento (Aquisição) e Produção e Adaptação), os esforços que cada uma delas direciona a cada uma delas são diferentes.

Essas montadoras buscam, do mesmo modo, diversificar os produtos, mas o fazem com diferentes estratégias de divisão de atividades tecnológicas em relação às suas respectivas matrizes estrangeiras. Elas buscam por conhecimentos tecnológicos junto às matrizes, mas com intensidade diferente. Além disso, elas desejam fazer com que os novos projetos de produtos sejam mais facilmente implementados na fábrica, mas também assumem meios distintos para esta finalidade.

Em síntese, este estudo mostra que as EOs e ETs são complementares e fundamentais para a competitividade das empresas.

Com base nesses aspectos aqui investigados, indicamos alguns possíveis desdobramentos desta pesquisa. Sem pretender esgotar todas as possibilidades, pode-se sugerir (1) estudar as demais montadoras instaladas no Brasil; (2) estudar as EOs e ETs de fornecedores do setor de linha branca; (3) analisar as trajetórias tecnológicas de algumas empresas que foram adquiridas por grupos multinacionais, mas que eram, inicialmente, empresas de capital nacional.

\begin{abstract}
This paper aims at studying the Operations and Technology Strategies (OS and TS) of two companies belonging to the home-appliance industry segment, making a comparison and discussing the link between both strategies in this segment. To meet this goal, case studies were accomplished in both companies, based on semi-structured interviews. The findings indicate that, to fulfill similar competitive priorities, these companies have implemented similar changes in their operations decision areas (although some differences could be found). Besides, they tend to adopt similar TSs concerning the Technological Capabilities they've prioritized, making different efforts in each prioritized capability (Innovation, Acquisition, Production and Adaptation).
\end{abstract}

Keywords: Operations Strategy, Technology Strategy, Home-Appliance Segment.

\title{
Referências
}

ALVES FILHO, A.G.; CERRA, A.L.; NOGUEIRA, E.; MAIA, J.L. Uma tentativa de integração das estratégias de produção e tecnológica. Anais do XXV Encontro Nac. de Eng. de Produção. XXV ENEGEP. Porto Alegre, RS, Brasil, 29 out a 01 de nov de 2005. p. 3588-3595

ALVES FILHO, A.G. Estratégia tecnológica, desempenho e mudança: estudo de caso em empresas da indústria de calçados. 1991. Tese (Doutorado em Engenharia de Produção) - Escola Politécnica, Universidade de São Paulo. São Paulo.

AlVES FILHO, A. G.; PIRES, S.; VANALlE, R. M. Sobre as Prioridades Competitivas da Produção: Compatibilidades e Seqüências de Implementação. Gestão \& Produção. V. 2, n. 2, p. 173-180,1995. 
BELL, R. M.; PAVITT, K. Technological accumulation and industrial growth: contrasts between developed and developing countries. Industrial and Corporate Change, p.157 - 210, 1993.

crossef

BOYER, K. K.; LEWIS, M. W. Competitive priorities: Investigating the need for trade-offs in operations strategy.

Production and Operations Management, v. 11, n. 1, p. 9-20, 2002.

CLARKE et al. Technology strategy in UK firms. Technology Analysis \& Strategic Management ,v.7, n.2, p.169$190,1995$.

cross ${ }^{\text {ref }}$

COHEN, W.M.; LEVINTHAL, D.A. Absorptive capacity: a new perspective on learning and innovation. Administrative Science Quarterly. Special Issue - Technology, Organizations and Innovation. v.35, n.1, p.128-152, March 1990.

COLLIS, D.; MONTGOMERY, C. Competing on Resources: Strategy in the 1990s. Harvard Business Review. JulyAugust, p. 118-128, 1994.

DA SILVEIRA, G.; SLACK, N. Exploring the trade-off concept. International Journal of Operations Management, V. 21, n. 7 , p. $949-964,2001$.

cross ${ }^{\text {ref }}$

DAHLMAN, C.J.; ROSS-LARSON,B.; WESTPHAL, L.E. Managing technological development: lessons from the newly industrializing countries. World Development, v.15, n.6, 1987. p.759-775.

cross ref

DANGAYACH, G. S.; DESMUKH, S. G. Manufacturing Strategy : Literature review and some issues. International Journal of Operations and Production. Vol. 21, n. 7, p. 884-932, 2001.

cross ref

DAVENPORT, S.; CAMPBELL-HUNT, C.; SOLOMON, J. The dynamics of Technology Strategy: an exploratory study. R\&D Management, V.33, n.5, 2003.

cross ${ }^{\text {ref }}$

DEMETER, K. Manufacturing strategy and competitiveness. International Journal of Production Economics. Vol. 81-82, p. 205-213, 2003.

cross ref

FERDOWS, K.; DE MEYER, A. Lasting improvements manufacturing performance: in search of a new theory. Journal of Operations Management, v. 9, n. 2, p. 168-194, 1990.

cross ref

FORD, D. Develop your strategy. Engineering Management Review, v.17, n.3, p.16-26, Sept., 1989.

FORD, D.; THOMAS, R. Technology strategy in networks. International Journal Technology Management, vol.14, nos 6/7/8, 1997. p. 596-612.

GARVIN, D. A. Manufacturing Strategy Planning. California Management Review, v. 35, n. 4, p. 85-106, 1993.

GIBBONS, P.T.; O’CONNOR, T. Strategic posture, technological strategy and performance. Journal of Enterprising Culture. V.11, n.2, june 2003. p.131-146.

cross ${ }^{\text {ref }}$

HAYES, R.; WHEELWRIGHT, S. C. Restoring our Competitive Edge - Competing through Manufacturing. John Willey \& Sons, 1984.

HAYES, R. H.; PISANO, G. P.; UPTON, D. M.; WHEELWRIGHT, S. C. Operations, Strategy and Technology: Pursuing the Competitive Edge. John Willey\&Sons, EUA, 2004. 
HILL, T. Operations Management: Strategic Context and Managerial Analysis. Macmillan Ltd., 2000.

IGLECIAS, L. Um modelo para formulação de Estratégia Tecnológica: o caso de uma montadora na indústria automobilística. 2001. Dissertação (Mestrado em Engenharia de Produção) - Universidade Federal de São Carlos.

KATHURIA, R. Competitive priorities and managerial performance : a taxonomy of small manufaturers. Journal of Operations Management, Vol. 18, p 627-641, 2000.

crossef

MARTINEZ, M. A construção da qualificação: um estudo de caso na linha branca. Dissertação (Mestrado em Engenharia de Produção). Departamento de Engenharia de Produção. Universidade Federal de São Carlos. São Carlos, 2004. $87 \mathrm{p}$.

MATUSITA, A.P. Mudança estrutural no setor de linha branca nos anos 90: características e condições. Dissertação (Mestrado em Política Científica e Tecnológica). Unicamp. Campinas, 1997.

NOGUEIRA, E. Empresas Fabricantes de Revestimentos Cerâmicos e a Gestão de seus Sistemas Produtivos. A Proposição de um Modelo. Tese (Doutorado Administração de Empresas), FGV/EAESP. 2002.

OLIVEIRA, D. P. R. Planejamento Estratégico: Conceitos, metodologias e práticas. Décima Edição, São Paulo, Atlas, Brasil, 2001.

PAVITT, K.; BELL, M. Technological accumulation and industrial growth: contrasts between developed and developing countries. Industrial and Corporate Change._Vol.2, n.2, p.157-210, 1993.

ROTTA, I. S. Mini-fábrica: uma nova proposta de arranjo produtivo e organizacional híbrido em uma empresa do setor eletroeletrônico. Tese (Doutorado em Engenharia de Produção). Departamento de Engenharia de Produção. Universidade Federal de São Carlos. São Carlos, 2004. 268p.

SKINNER, W. Manufacturing: Missing Link Corporate Strategy. Harvard Business Review, v. 47, n. 3 , 1969.

SLACK, N.; CHAMBERS, S.; JOHNSTON, R. Administração da Produção. 2. ed. São Paulo: Atlas, 2002.

SMITH, D.J.; ROGERS, M.F. Technology Strategy and innovation: the use of derivative strategies in the aerospace industry. Technology Analysis \& Strategic Management. V.16, n.4, December 2004. p.509-527.

crossef

ZAHRA, S.A. Technology Strategy and financial performance: examining the moderating role of the firm's competitive environment. Journal of Business Venturing. Vol.11, p.189-219, 1996.

cross'

WARD, P. T.; DURAY, R. Manufacturing Strategy in Context: Environment, competitive strategy and manufacturing strategy. Journal of Operations Management, vol. 18, n. 2, p 123-138, 2000.

crossef

WESTPHAL, L.E.; KIM, L. e DAHLMAN, C.J. Reflections on the Republico f Korea's acquisition of technological capability, In: ROSENBERG, N.; FRISCHTAK, C. International technology transfer: concepts, measures, and comparisons. New York: Praeger, 1985.

Nome completo: Aline Lamon Cerra

Filiação institucional: Universidade Federal de São Carlos

Departamento: Engenharia de Produção

Função ou cargo ocupado: Pós-Doutoranda 
Endereço completo para correspondência (bairro, cidade, estado, país e CEP): Rod. Washington Luis (SP-310) Km 235 Monjolinho São Carlos-SP CEP 13565-905

Telefones para contato: (16)33519523

e-mail: alinelc@terra.com.br

Nome completo: Naiara Calife

Filiação institucional: Universidade Federal de São Carlos

Departamento: Engenharia de Produção

Função ou cargo ocupado: Mestranda

Endereço completo para correspondência (bairro, cidade, estado, país e CEP): Rod. Washington Luis (SP-310) Km 235 Monjolinho São Carlos-SP CEP 13565-905

Telefones para contato: (16)33519523

e-mail: naiaracalife@hotmail.com

Nome completo: Edemilson Nogueira

Filiação institucional: Universidade Federal de São Carlos

Departamento: Engenharia de Produção

Função ou cargo ocupado: Professor

Endereço completo para correspondência (bairro, cidade, estado, país e CEP): Rod. Washington

Luis (SP-310) Km 235 Monjolinho São Carlos-SP CEP 13565-905

Telefones para contato: (16)33519523

e-mail: $\underline{\text { edn@ } @ \text { power.ufscar.br }}$

Nome completo: Jonas Lucio Maia

Filiação institucional: Universidade Federal de São Carlos

Departamento: Engenharia de Produção

Função ou cargo ocupado: Doutornando

Endereço completo para correspondência (bairro, cidade, estado, país e CEP): Rod. Washington Luis (SP-310) Km 235 Monjolinho São Carlos-SP CEP 13565-905

Telefones para contato: (16)33519523

e-mail: jonasmaia@dep.ufscar.br

Nome completo: Alceu Gomes Alves Filho

Filiação institucional: Universidade Federal de São Carlos 
Departamento: Engenharia de Produção

Função ou cargo ocupado: Professor

Endereço completo para correspondência (bairro, cidade, estado, país e CEP): Rod. Washington Luis (SP-310) Km 235 Monjolinho São Carlos-SP CEP 13565-905

Telefones para contato: (16)33519523

e-mail: alceu@power.ufscar.br

Recebido para publicação em: 03/03/2009

Aceito para publicação em: 09/06/2009 